\title{
SPATIAL AND TEMPORAL VARIATION AND PROBABILITY CHARACTERISTICS OF EXTREME PRECIPITATION EVENTS IN THE MIN RIVER BASIN FROM 1961 TO 2016
}

\author{
ChEn, T. ${ }^{1,2}-$ Ao, T. Q. ${ }^{1 *}-$ ZHANG, X. ${ }^{1,3,4}-$ LI, X. D. ${ }^{1}-$ ZHOU, L. ${ }^{1}-$ LI, M. R. ${ }^{1}-$ YANG, K. B. ${ }^{1}$ \\ ${ }^{1}$ State Key Laboratory of Hydraulics and Mountain River Engineering, College of Water \\ Resource and Hydropower, Sichuan University, Chengdu/610065, China \\ ${ }^{2}$ Heavy Rain and Drought-Flood Disasters in Plateau and Basin Key Laboratory of Sichuan \\ Province, Chengdu/610072, China \\ ${ }^{3}$ State Key Laboratory of Hydrology-Water Resources and Hydraulic Engineering \\ Nanjing Hydraulic Research Institute, Nanjing/210029, China \\ ${ }^{4}$ Research Center for Climate Change, Ministry of Water Resources, Nanjing/210029, China \\ ${ }^{*}$ Corresponding author \\ e-mail:aotianqi@scu.edu.cn \\ (Received $18^{\text {th }}$ Apr 2019; accepted $11^{\text {th }}$ Jul 2019)
}

\begin{abstract}
Based on the daily precipitation data of 25 national meteorological stations in the Min River Basin (the MRB), the temporal and spatial variation trends of extreme precipitation events from 1961 to 2016 were analyzed using multiple extreme precipitation indices and the Mann-Kendall trend analysis. The extreme precipitation in different recurrence periods was calculated by using the regional frequency analysis combined with the spatial distribution characteristics of extreme precipitation events. The spatial distribution of the extreme precipitation index in the MRB varies considerably. The average characteristics of extreme precipitation are changing from short-term extreme precipitation to sustained extreme precipitation. The main reasons for this change are the significant increases in wet days and consecutive wet days, particularly the number of heavy precipitation days (R10mm). On this basis, the Min River is divided into four hydro-climatically consistent regions and the maxima of RX1DAY's and RX5DAY's 20-year and 100 -year recurrence periods are found. The traditional at-site hydrological frequency analysis averaged the spatial differences within the basin and underestimated the extreme precipitation in the middle reaches. This indicates that the regional frequency analysis has some reference significance for solving the problem of neglecting the uneven spatial distribution of extreme precipitation in precipitation estimation.
\end{abstract}

Keywords: climate change, extreme precipitation indices, regional frequency analysis, precipitation estimation, Mann-Kendall trend analysis

\section{Introduction}

The IPCC Fifth Assessment Report pointed out that the global average surface temperature increased by $0.85^{\circ} \mathrm{C}$ between 1880 and 2012 (IPCC, 2013), and global warming has become an indisputable fact. In the context of global warming, extreme events such as floods, droughts, typhoons, high temperatures, low temperatures and freezing rain and snow often occur (Changnon et al., 2000; Zengxin, 2011; Fu et al., 2013; Tian et al., 2016). As an important part of the water cycle, precipitation directly 
affects the hydrological process of runoff and increases the frequency of flooding disasters (Wang et al., 2004; Kampata et al., 2008; Millett et al., 2009; Chen et al., 2009; Xu et al., 2010; Zhang et al., 2012).

The IPCC report also points out that the land surface temperature in China has risen by $1.38^{\circ} \mathrm{C}$ in the past 60 years, $0.23^{\circ} \mathrm{C}$ every 10 years, which is higher than the global average. The climate change is likely to develop further. Many scholars have analyzed the extreme precipitation in different regions of China: the studies have shown that there are obvious regional differences in the extreme precipitation and precipitation frequency in different regions of Qinling-Huaihe River North of Henan (Liet al., 2015), Pearl River Basin (Huang et al., 2014), and Yellow River Basin (He et al., 2014), indicating that there are obvious spatial differences in the distribution of extreme precipitation events.

Though the analysis of the characteristics of extreme precipitation over time in different regions, it is also found that there are spatial differences in the temporal variation of extreme precipitation events (Chu et al., 2012; Li et al., 2012; Bai et al., 2015; Tian et al., 2016). Zhai et al. (2005) found that there was no obvious change trend in annual precipitation and the intensity of precipitation was on the rise. However, the trend of extreme precipitation events showed obvious spatial differences. Influenced by East Asian monsoon activities, China was extremely vulnerable to large-scale flood disasters, especially in the Yangtze River Basin (YRB). Yu et al. (2004) pointed out that while the precipitation in northern China was decreasing, the precipitation in mainland China took the form of "flooding in the South and drought in the North". The probability of flood disasters in the YRB was much greater than that in other regions of China. Zhai (1999) showed that the annual precipitation in the YRB showed a significant upward trend. The extreme precipitation in the middle and lower reaches of the YRB showed a significant upward trend, and the change trend in the upper reaches of the YRB was not obvious. Pan et al. (2017) used the methods of trend and catastrophe analysis, R/S analysis and hydrological frequency analysis to study the temporal and spatial evolution characteristics and future trends of extreme precipitation in the YRB. The results show that the regional extreme precipitation index in the YRB shows an upward trend, and the annual changes of the extreme precipitation index in the middle and lower reaches are greater than in the upper reaches. Wu (2016) used the Mann-Kendall (MK) test to study the changes of extreme precipitation in 11 regions of China, and concluded that the flood disaster in the upper reaches of the YRB had an obvious increasing trend. Bai (2015) used Logistic regression model to study the characteristics of extreme precipitation in the YRB. The results show that the frequency of extreme precipitation in the upper and middle reaches has a significant non-linear increasing trend, but the variation trend of extreme precipitation frequency in the Sichuan Basin located in the upper reaches of the YRB is not obvious. Qian (2005) found that the intensity of extreme precipitation and the frequency of persistent rainy days in the upper reaches of the YRB showed a downward trend. Zhang (2006) simulated extreme precipitation in the YRB through PRECIS climate model simulation and concluded that extreme precipitation events in the middle 
and lower reaches had an overall upward trend, but the upstream trend was not obvious. Chen et al. (2017) predicted that extreme precipitation in China would increase significantly in the lower reaches of the YRB in the 21 st century by using the IPCC AR4 model and coupling it with the atmospheric circulation model.

From the above conclusions, we can see that the study of the YRB shows that there is an increasing trend in extreme precipitation in the YRB (Zhai et al., 1999; Yu, 2004; Pan et al., 2017), but there are also obvious regional differences there. The consistent conclusion for the middle and lower reaches of the YRB is that the extreme precipitation in the middle and lower reaches shows an upward trend (Zhai et al., 1999; Zhang et al., 2006; Pan et al., 2017; Chen et al., 2017), which is also the main contribution of the overall extreme precipitation in the YRB. At the same time, the conclusions of the upper reaches of the YRB are not entirely unified. Some studies of the upper reaches show an upward trend, but the upward trend is lower than that of the middle and lower reaches of the YRB (Xu et al., 2016; Pan et al., 2017). Other studies show that the extreme precipitation in the upper reaches of the YRB has not changed significantly with time and may even have shown a downward trend (Zhai et al., 1999; Qian et al., 2005; Zhang et al., 2006; Luyao et al., 2015). The conclusion of extreme precipitation variation in the upper reaches of the YRB is not entirely uniform, which may be related to the incomplete data periods, different methods and incomplete definitions of extreme precipitation indices used. When the data period used is not exactly the same, because of the quasi-periodic oscillation of precipitation in the YRB (Chen et al., 2017), the trend of extreme precipitation in the analysis results is related to the length of the time series used in the analysis. When different research methods are used, the results may be different (Qian et al., 2005; Luyao et al., 2015). The methods of extreme precipitation research are mainly divided into two categories. One is statistical analysis of precipitation data, such as using MK trend test, MK mutation analysis, wavelet analysis and other statistical methods (Karl et al., 1998; Bonsal et al., 2001; Pal et al., 2011; Tramblay et al., 2012; Yang et al., 2012; Croitoru et al., 2013). Because statistical methods depend heavily on the length of observation data and the selected site data, the results of different research periods or sites in the same region may vary greatly. The other is to simulate the characteristics of extreme precipitation using models. Because the current climate models cannot accurately simulate the temporal and spatial changes of future extreme climate events, the prediction of future extreme precipitation by multi-model sets also has a series of problems of accuracy and deviation, such as the error of a single model may affect the whole prediction conclusion, and multimodal ensemble forecasting results may smooth some extreme weather events ( $\mathrm{Li}$ et al., 2012). At the same time, different indicators of extreme precipitation will also affect the results. The indicators of extreme precipitation were proposed by the World Meteorological Organization (WMO) Meteorological Committee (CCL) and Climate Variability and Predictability Research Program (CLLVAR) in 2006. The recommended extreme precipitation indicators can point out the characteristics of extreme precipitation, including intensity, frequency, and duration. 
Before that, the extreme precipitation indices used were not perfect (Zhai et al., 1999; Qian et al., 2005; Su et al., 2006).

In addition to the above three reasons, which have an impact on the research results of extreme precipitation in the $\mathrm{YRB}$, there is also a reason for the spatial differences of regional changes in the YRB. When the study area is large (for example, dividing the YRB into upper, middle and lower reaches), it will be difficult to reflect the spatial and temporal variations of extreme precipitation in different regions of the basin, because the overall study of the region will smooth out the regional characteristics of extreme precipitation. At the same time, if its trend keeps rising in the future, it will be difficult to reflect the temporal and spatial variation trend by using the entire dataset. The predictions of precipitation estimated by using the whole data will be more uncertain. Moreover, the significance of the trend and changes in the extreme precipitation index in the predictions of precipitation also has not been given sufficient attention. Therefore, the Min River Basin (the MRB), which belongs to the upper reaches of the YRB and is the largest tributary of the upper reaches of the Yangtze River, is selected as the study area for the current study. The MRB is in the transition area from the high-altitude area to the basin on the eastern side of the Qinghai-Tibet Plateau. There are great differences in altitude, topography and climate conditions in this area. The study of extreme precipitation variation in the MRB is of great significance to the analysis of extreme precipitation variation trends in the Yangtze River and the upper reaches of the Yangtze River. Previous research on the precipitation characteristics of the MRB has concentrated on the lower reaches of the MRB, and has mainly focused on the general characteristics of precipitation in the MRB. In the context of global warming, the MRB shows different regional response characteristics, which will have a huge impact on regional environmental ecology. Therefore, on the basis of previous research work, this paper focuses on the MRB, using the daily precipitation data of 26 meteorological stations in the MRB from 1961 to 2016, using MK trend analysis, to analyze the temporal and spatial variation of extreme precipitation in the MRB. Considering the significant changes of extreme precipitation in different regions, the MRB was divided into climatic consistent regions and the estimated precipitation of the basin was calculated by using the regional frequency analysis.

\section{Materials and Methods}

The Min River (Fig. 1) is the largest tributary of runoff in the Yangtze River. The total drop of the Min River is 3560 meters, and the basin area is 135881 square kilometers. It is an important area for hydropower development in Southwest China. According to the geographical characteristics of the main river, the upper reaches extend from the source to Dujiangyan City, the middle reaches from Dujiangyan City to Leshan City, and the lower reaches from Leshan City to Yibin City. 


\section{Precipitation Data}

The daily precipitation data of 25 stations (Table 1) from 1961 to 2016 is provided by the China Meteorological Administration. Relevant station data is available at http://data.cma.cn/. The precipitation data have been qualitatively controlled.

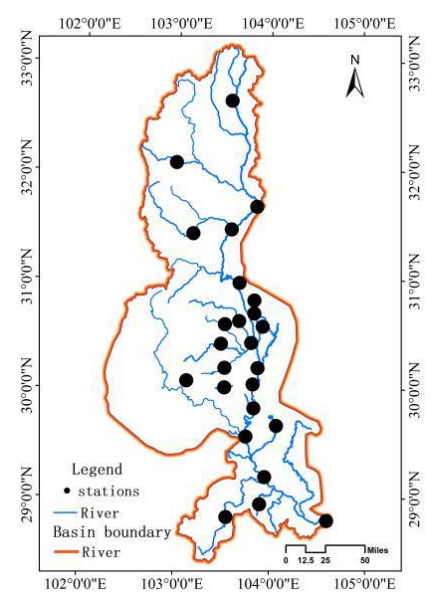

Figure 1. Min River drainage map

Table 1. The basic information of the meteorological stations in the MRB

\begin{tabular}{|c|c|c|c|c|c|}
\hline Station number & Longitude ( $\left.{ }^{\circ} \mathbf{E}\right)$ & Latitude $\left({ }^{\circ} \mathbf{N}\right)$ & Altitude (m) & Station name & Station class \\
\hline \multicolumn{6}{|c|}{ the upper reaches } \\
\hline 56182 & 103.57 & 32.65 & 2850 & Songpan & base station \\
\hline 56185 & 102.98 & 32.08 & 2400 & Heishui & general stations \\
\hline 56180 & 103.85 & 31.68 & 1591 & Maoxian & general stations \\
\hline 56183 & 103.58 & 31.47 & 1326 & Wenchuan & general stations \\
\hline 56184 & 103.17 & 31.43 & 1885 & Lixian & general stations \\
\hline \multicolumn{6}{|c|}{ the middle reaches } \\
\hline 56188 & 103.67 & 30.98 & 699 & Dujiangyan & base station \\
\hline 56189 & 103.93 & 30.98 & 582 & Pengzhou & general stations \\
\hline 56187 & 103.83 & 30.7 & 539 & Wenjiang & base station \\
\hline 56288 & 103.92 & 30.58 & 495 & Shuangliu & general stations \\
\hline 56181 & 103.67 & 30.63 & 534 & Chongzhou & general stations \\
\hline 56272 & 103.83 & 30.82 & 559 & Pixian & general stations \\
\hline 56276 & 103.8 & 30.43 & 468 & Xinjin & general stations \\
\hline 56285 & 103.52 & 30.6 & 524 & Dayi & general stations \\
\hline 56284 & 103.48 & 30.42 & 501 & Qionglai & general stations \\
\hline 56281 & 103.52 & 30.2 & 511 & Pujiang & general stations \\
\hline 56391 & 103.82 & 30.05 & 415 & Meishan & general stations \\
\hline 56289 & 103.87 & 30.2 & 437 & Pengshan & general stations \\
\hline 56381 & 103.52 & 30.02 & 496 & Dangling & general stations \\
\hline 56383 & 103.83 & 29.83 & 455 & Qingshen & general stations \\
\hline 56386 & 103.75 & 29.57 & 424 & Leshan & base station \\
\hline \multicolumn{6}{|c|}{ the lower reaches } \\
\hline 56390 & 104.07 & 29.67 & 404 & Jingyan & general stations \\
\hline 56389 & 103.95 & 29.2 & 388 & Qianwei & general stations \\
\hline 56480 & 103.55 & 28.83 & 541 & Mabian & general stations \\
\hline 56490 & 103.9 & 28.95 & 397 & Muchuan & general stations \\
\hline 56492 & 104.6 & 28.8 & 341 & & base station \\
\hline
\end{tabular}




\section{Extreme Precipitation Index}

Twelve extreme precipitation indices are used in this study. They are recommended by the World Meteorological Organization (WMO) Meteorological Committee (CCL) and Climate Variability and Predictability Research Program (CLLVAR) (Alexander et al., 2006). These indicators have been applied to analyze the characteristics of extreme precipitation ( $\mathrm{Wu}$ et al., 2016). In this article, three supplementary indices (SPIs) are added to describe the variation trend of precipitation in the MRB. Detailed descriptions of ETIs and SPIs are presented in Table 2.

Table 2. Definitions of extreme precipitation indices employed in the study

\begin{tabular}{|c|c|c|c|}
\hline \multicolumn{4}{|c|}{ ETIs } \\
\hline CWD & Consecutive wet days & $\begin{array}{l}\text { Maximum number of consecutive days with } \\
\qquad \mathrm{RR} \geq 1 \mathrm{~mm}\end{array}$ & days \\
\hline $\mathrm{R} 10 \mathrm{~mm}$ & Number of heavy precipitation days & Annual count of days when $R R \geq 10 \mathrm{~mm}$ & days \\
\hline $\mathrm{R} 25 \mathrm{~mm}$ & Number of very heavy precipitation days & Annual count of days when $R R \geq 25 \mathrm{~mm}$ & days \\
\hline RX1DAY & Maximum 1-day precipitation & Annual maximum 1-day precipitation & $\mathrm{mm}$ \\
\hline RX5DAY & Maximum 5-day precipitation & Annual maximum 5-day precipitation & $\mathrm{mm}$ \\
\hline R95T & very wet day precipitation & $\begin{array}{l}\text { Annual total precipitation when } \mathrm{RR} \geq 95 \text { th } \\
\text { percentile of } 1961-2016 \text { daily precipitation }\end{array}$ & $\mathrm{mm}$ \\
\hline R99T & Extremely wet day precipitation & $\begin{array}{l}\text { Annual total precipitation when } \mathrm{RR} \geq 99 \text { th } \\
\text { percentile of } 1961-2016 \text { daily precipitation }\end{array}$ & $\mathrm{mm}$ \\
\hline PRCPTOT & Annual total wet day precipitation & Annual total precipitation in wet days $(\mathrm{RR} \geq 1 \mathrm{~mm})$ & $\mathrm{mm}$ \\
\hline SDII & Simple daily intensity index & $\begin{array}{l}\text { Annual total precipitation divided by the number } \\
\text { of wet days in the year }\end{array}$ & $\mathrm{mm} /$ day \\
\hline \multicolumn{4}{|c|}{ SPIs } \\
\hline R95PT & Precipitation fraction due to very wet days & Ratio between R95T and PRCPTOT & $\%$ \\
\hline R99PT & $\begin{array}{l}\text { Precipitation fraction due to extremely wet } \\
\text { days }\end{array}$ & Ratio between R99T and PRCPTOT & $\%$ \\
\hline WD & Wet days & Annual count of days when $R R \geq 1 \mathrm{~mm}$ & days \\
\hline
\end{tabular}

Note: RR denotes daily precipitation

\section{Methods}

\section{MK Trend Test}

A MK test is a non-parametric test recommended and widely used by the WMO. A MK test does not require samples to follow a certain distribution, nor is it disturbed by a few abnormal values. A MK trend test was used to analyze the trend change of time series of precipitation, runoff, temperature, and water quality (Mann, 1945; Kendall, 1945; Vijay et al., 2010; Wu et al., 2016). It is suitable for non-normal distribution data such as hydrology and meteorology and is easy to calculate (Xu et al., 2007; Burn et al., 2008; Wu et al., 2008; Zhang et al., 2008; Wang, 2009). The calculation formula of the MK test can be found in Reference (Mann, 1945). 


\section{Regional Frequency Analysis}

The regional frequency analysis combines linear moment with regional analysis method, avoids the limitation of traditional at-site frequency analysis method, improves the unbiasedness and robustness of parameter estimation, improves the accuracy of frequency design value (Lin et al., 2006), and effectively improves the accuracy and reliability of hydrological frequency analysis. At present, it has been widely used in hydrological frequency analysis (Li et al., 2015; Shao et al., 2016; Yang et al., 2009).

Firstly, this study chooses the indicators which can reflect the obvious spatial differences in extreme precipitation. Combining with the longitude, latitude, elevation and linear moment parameters of each station, all stations are preliminarily divided by clustering analysis method, and the discordance detection and heterogeneity detection (Xiong et al., 2004) are used to test whether each zone is a reasonable hydrometeorological consistency region.

On this basis, in view of the divided hydrometeorological consistent region, this study assumes that the stations in the hydrometeorological consistent region conform to Kappa distribution. Monte Carlo simulation is used to simulate the study area $N_{\text {sim }}$ times, each time generating the same length of historical rainfall data series corresponding to each site. Furthermore, Monte Carlo simulation test is used to determine the optimal frequency distribution for each hydrometeorological consistency region in the five three-parameter frequency distribution patterns (Chen, 2014): generalized Pareto distribution (GPA), generalized extreme value distribution (GEV), generalized logistic distribution (GLO), generalized normal distribution (GNO) and Pearson III distribution (PE3). Finally, using the index flood method (Cunnane, 1989) and the optimal frequency distribution line, the design values of rainstorm frequencies for different recurrence periods of each station are calculated.

The calculation formula of the discordance detection is as follows:

$$
D_{i}=\frac{1}{3} N\left(u_{i}-\bar{u}\right)^{T} A^{-1}\left(u_{i}-\bar{u}\right)
$$

In the formula: $u_{i}=\left[t^{i}, t_{3}^{i}, t_{4}^{i}\right]^{T} \quad(\mathrm{i}=1,2,3 \ldots \mathrm{N})$ is a three-dimensional vector consisting of three linear moment coefficients: linear deviation coefficient L-Cv, linear deviation coefficient L-Cs and linear kurtosis coefficient L-Ck.

$$
\begin{gathered}
\bar{u}=N^{-1} \sum_{i=1}^{N} u_{i} \\
A=\sum_{i=1}^{N}\left(u_{i}-\bar{u}\right)\left(u_{i}-\bar{u}\right)^{T}
\end{gathered}
$$


If the discordance coefficient $D_{i} \leq \frac{N-1}{3}$, there is no singularity in the region. If $D_{i}>\frac{N-1}{3}$, it is considered that the site is a discordance point. It is necessary to further check the rationality and reliability of the site data and make a correct trade-off.

The formula of the heterogeneity detection is as follows:

$$
H_{l}=\frac{\left(V_{1}-\mu_{v}\right)}{\sigma_{v}}
$$

Among them,

$$
\begin{gathered}
V_{1}=\left\{\sum_{i=1}^{N} n_{i}\left(t^{i}-t^{R}\right)^{2} / \sum_{i=1}^{N} n_{i}\right\}^{\frac{1}{2}} \\
t^{R}=\sum_{i=1}^{N} n_{i} t^{i} / \sum_{i=1}^{N} n_{i}
\end{gathered}
$$

where $n_{i}$ is the length of rainfall data series of the $i$-th station in the consistent area, $t^{i}$ is the linear potential coefficient $\mathrm{L}-\mathrm{Cv}$ at the $i$-th station in the consistent area, $N$ is the total number of stations in the consistent area. $\mu_{\mathrm{v}}$ and $\sigma_{v}$ are the mean and mean square deviation of $V_{I}$ calculated by Monte Carlo simulation.

If $H_{1}<1$ the area is acceptably consistent, if $1 \leq H_{1}<2$ the area is possibly heterogeneous, and if $H_{1 \geq 2}$ the area is heterogeneous. The stations in the area need to be adjusted when $H_{1} \geq 1$ is acceptable until they meet the criteria.

\section{Results Analysis}

\section{Spatial Distribution}

As can be seen from Figure 2, the maximum number of consecutive wet days (CWD) in the MRB was relatively uniform. The frequency of extreme precipitation events (R10mm and $\mathrm{R} 25 \mathrm{~mm}$ ) in the lower and middle reaches of the MRB was significantly higher than that in the upper reaches. The spatial distribution of RX1DAY and RX5DAY were similar, showing a gradual increase in the upper and middle reaches of the basin, and a decrease in the lower reaches. The results show that the intensity of extreme 
precipitation events in the MRB was largest in the middle reaches, especially in the continuous extreme precipitation, followed by the lower reaches, and lowest in the upper reaches. The percentile index of extreme precipitation events (R95T, R99T, R95PT and R99PT) were larger in the middle and lower reaches than in the upper reaches of the MRB.
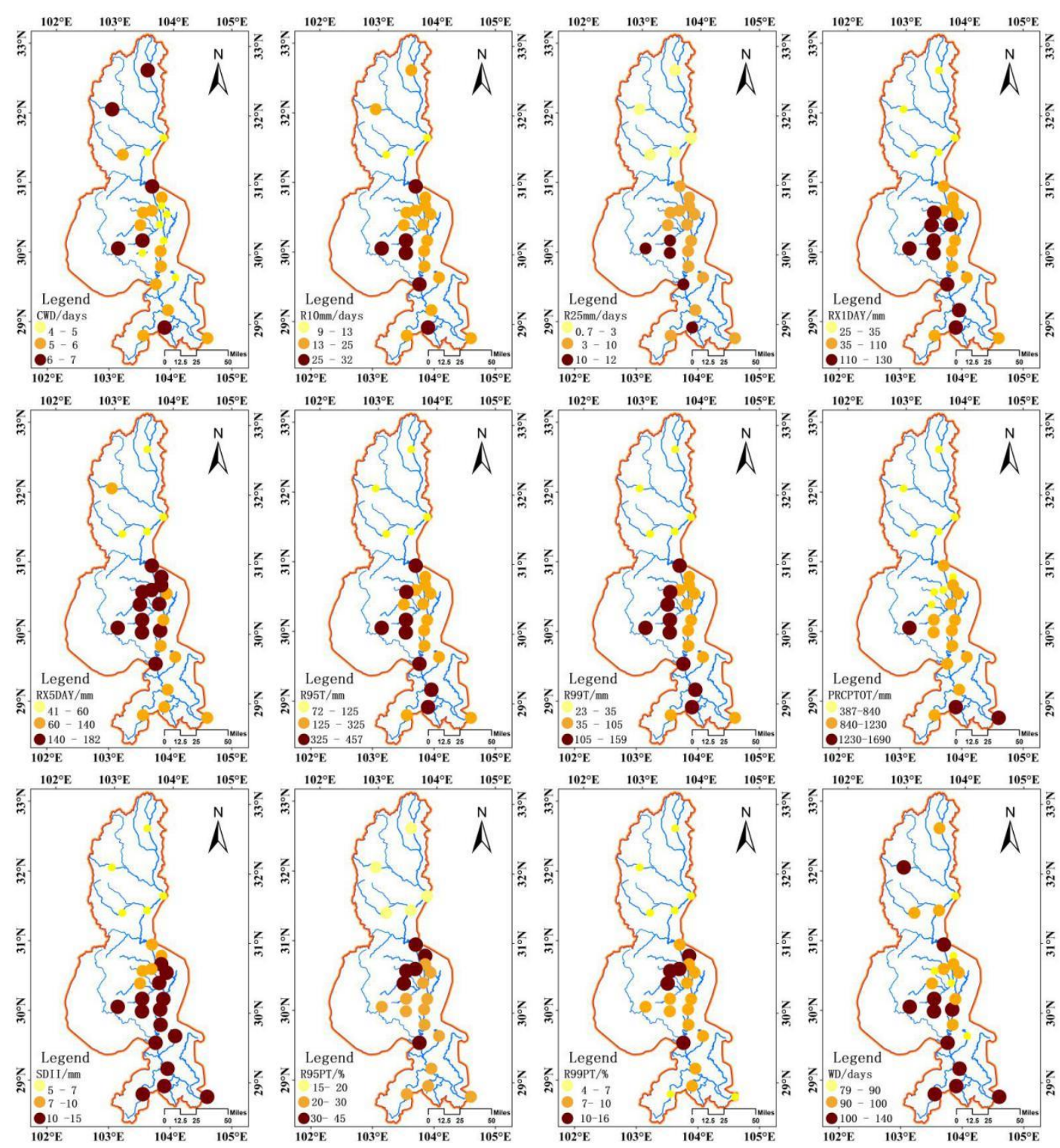

Figure 2. Spatial Distribution of Extreme Precipitation Index in the MRB

The PRCPTOT, the WD and the SDII in the MRB were higher in the lower reaches than in the middle reaches, and higher in the middle reaches than in the upper reaches. In a word, the main manifestation is that the high value of extreme precipitation index mainly appears in the middle and lower reaches of the basin, in which there is a high value 
center of extreme precipitation intensity in the middle reaches of the basin, while the low value appears in the upper reaches of the basin.

\section{Trends of Spatial Change}

As can be seen from Figure 3, the CWD shows an upward trend in the whole basin.
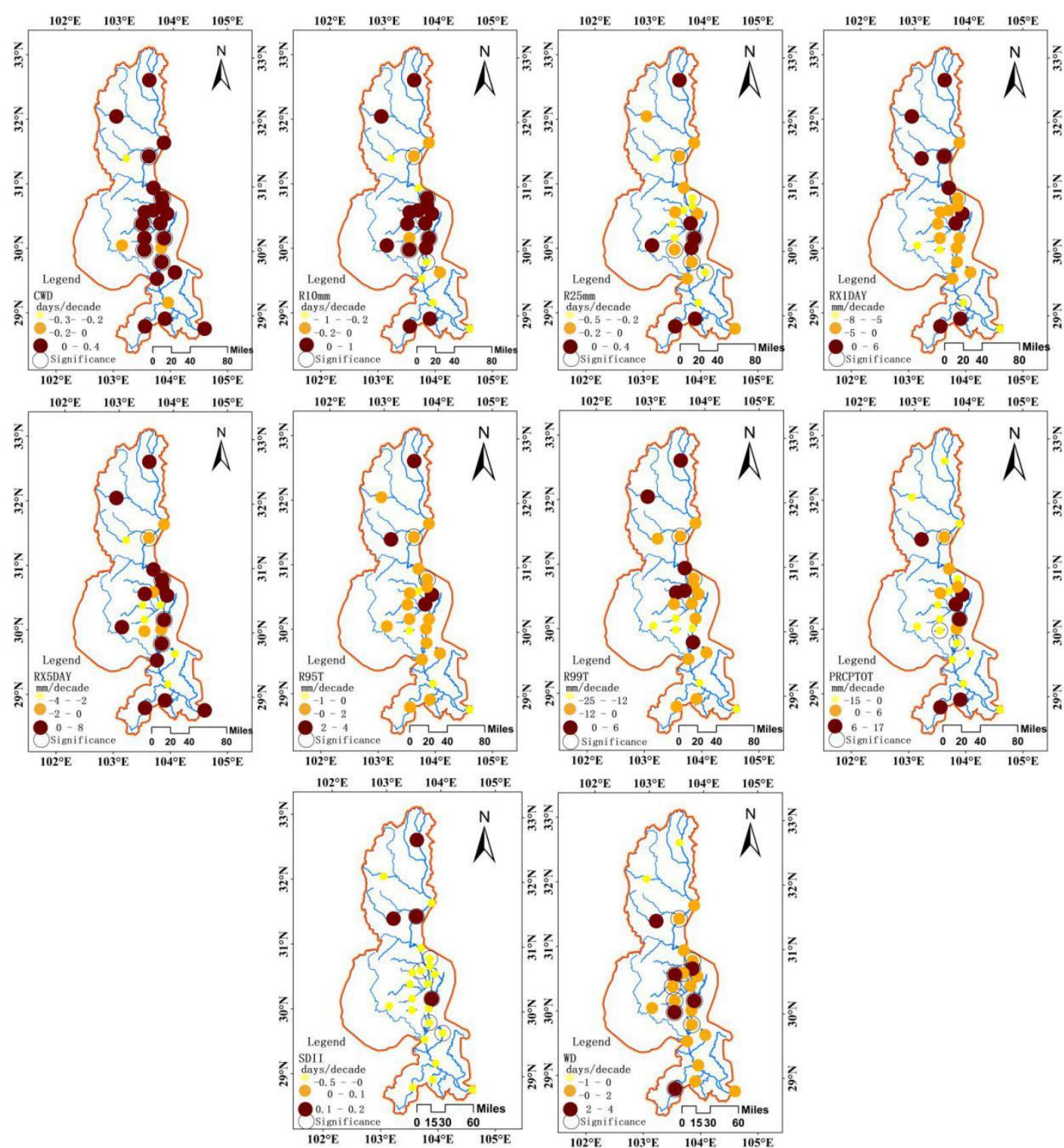

Figure 3. Spatial distribution of extreme precipitation index in the MRB

The frequency of R10 $\mathrm{mm}$ in the upper reaches of the basin decreases while that in the middle and in the lower reaches increases, while the frequency of R25mm mainly decreases in the whole basin. There are some regional differences in the spatial distribution of the RX1DAY change trend (Fig. 3). 
The upper reaches of the basin show a weak growth trend. The weak decrease trend is dominant in the middle and lower reaches. RX5DAY shows a downward trend in the upper reaches of the river basin. The results show that the spatial distribution difference of short-term extreme precipitation decreases and the spatial distribution difference of continuous extreme precipitation increases. The spatial pattern of extreme precipitation ratio (R95T and R99T) shows a decreasing trend. From the PRCPOT of each station in the basin, the middle reaches of the basin show an upward trend, while the upstream and downstream of the basin show a downward trend. The trend of SD II was mainly downward in the basin, and the trend of WD is mainly upward in the basin. In a word, the average characteristics of extreme precipitation in the middle and lower reaches of the MRB are changing from short-term extreme precipitation to sustained extreme precipitation, while the upper reaches of the MRB show the trend of increasing short-term rainfall intensity.

\section{Time Trend}

In this paper, the Tyson polygon method was used to assign different weight coefficients to each station in the basin. The temporal variation trend of extreme precipitation index in the basin was calculated using the MK trend test (Table 3) and the linear trend method (Table 3 and Fig. 4).

Table 3. Temporal trends of the ETIs in the MRB

\begin{tabular}{c|c|c|c|c|c|c|c|c|c|c}
\hline Index & CWD & R10mm & R25mm & RX1DAY & RX5DAY & R95T & R99T & PRCPTOT & SDII & WD \\
\hline MK & $\mathbf{2 . 1 4}$ & 0.77 & 0.20 & -0.72 & 1.53 & -0.72 & -1.37 & 0.614 & -0.67 & $\mathbf{1 . 6 6}$ \\
T & 0.15 & 0.29 & 0.015 & -0.63 & 2.4 & -3.4 & -3.8 & 5.6 & -0.021 & 1.6 \\
\hline
\end{tabular}

Notes: MK denotes MK statistics. T denotes trends $\left(\right.$ decade $\left.^{-1}\right)$. Values for the trends at the 0.05 significance level are shown in bold

The CWD of the MRB shows a significant upward trend. The R10mm shows a non-significant upward trend, while the $\mathrm{R} 25 \mathrm{~mm}$ shows a slightly upward trend. The RX1DAY shows a non-significant downward trend, while RX5DAY shows a non-significant upward trend. It shows that the characteristics of precipitation have changed from short-term heavy precipitation to persistent heavy precipitation. The R95T, R99T, R95PT and R99PT show non-significant downward trends. The results show that the proportion of one-day extreme precipitation to total precipitation has been weakening in recent years. The PRCPTOT showed no significant upward trend, SDII showed non-significant downward trend, WD showed a significant upward trend. In a word, the average characteristics of extreme precipitation in the MRB have changed from short-term extreme precipitation to persistent extreme precipitation. The main reasons for this change are the significant increase of the WD, the CWD and the R10mm, especially the increase of the $\mathrm{R} 10 \mathrm{~mm}$. 

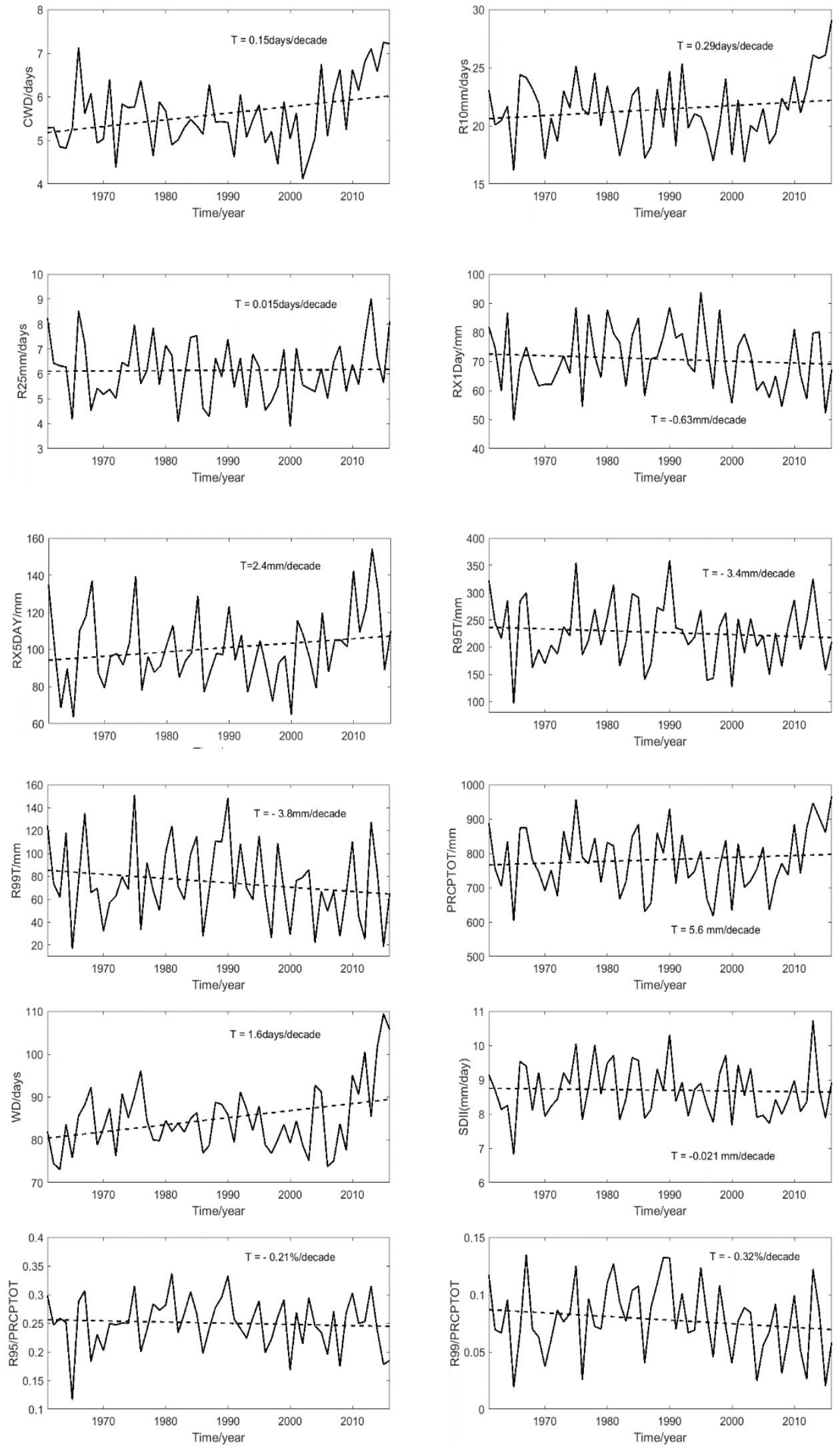

Figure 4. Interannual variation of extreme precipitation index in the MRB 


\section{Estimated Precipitation in the MRB Calculated by Regional Frequency Analysis}

According to the analysis above, it is concluded that there are large spatial variations in extreme precipitation in the Min River. Extreme precipitation has the spatial difference of persistent extreme precipitation (RX5DAY), while short-term extreme precipitation (RX1DAY) decreases. On this basis, the regional frequency analysis, which combines the linear moments with the regional analysis method, is used to calculate the estimated precipitation for RX5DAY reflecting persistent extreme precipitation and RX1DAY reflecting short-term extreme precipitation.

\section{Hydrometeorological Consistency Zone}

The Cluster analysis is used to classify the precipitation by considering latitude, elevation, and the first order linear distance of the average value of RX1DAY or RX5DAY. The results of the classification are tested for discordance and heterogeneity. Table 4 shows that the zoning results for RX1DAY and RX5DAY are acceptable according to the discordance test and heterogeneity test.

\section{The Selection of Optimal Frequency Distribution Line}

According to the hydrometeorological consistency region of the MRB, the optimal frequency distribution pattern of each hydrometeorological consistency region is determined by the Monte Carlo simulation test. The results (Table 5) show that the optimal linear distribution of RX1DAY in the four climate-consistent regions of the MRB was generalized logical distribution (GLO). The optimal linear distribution of RX5DAY in region 1 and region 2 of the MRB was generalized logical distribution (GLO). The optimal linear distribution of RX5DAY in region 3 was generalized extreme value distribution (GEV) and in region 4 was generalized normal distribution (GNO).

\section{Calculation of Estimated Precipitation}

According to the distribution function parameters of RX1DAY and RX5DAY precipitation series estimated by L-moments, combined with quantile formula, the precipitation of each station at the level of 1-100a recurrence period was estimated. According to the results of Monte Carlo test, the optimal distribution of RX1DAY and RX5DAY series at different stations in the MRB was selected, and the precipitation extremes at different recurrence periods were calculated by using the optimal distribution.

From the results of regional frequency analysis (al-dl in Figure 5), it can be seen that the maximum value of the 20-year and the 100-year recurring precipitation was concentrated in the middle reaches of the Min River. The 20-year recurrence period of RX1DAY was $230 \mathrm{~mm}$ in Leshan area and the 100-year recurrence period of RX1DAY was $340 \mathrm{~mm}$. The 20-year recurrence period of RX5DAY was $330 \mathrm{~mm}$ in Mingshan and the 100-year recurrence period of RX5DAY was $420 \mathrm{~mm}$ in Mingshan. 
Table 4. The results of discordance detection and heterogeneity test in three hydrometeorological consistent regions of the MRB

\begin{tabular}{|c|c|c|c|c|c|c|c|c|}
\hline Region & $\begin{array}{c}\text { Station } \\
\text { number } \\
\text { (RX1DAY) }\end{array}$ & $\begin{array}{c}\text { Di } \\
\text { (RX1DAY) }\end{array}$ & $\begin{array}{c}\text { Critical } \\
\text { Value of } \\
\text { Di }\end{array}$ & $\begin{array}{c}\text { H1 } \\
\text { (RX1DAY) }\end{array}$ & $\begin{array}{c}\text { Station } \\
\text { number } \\
\text { (RX5DAY) }\end{array}$ & $\begin{array}{c}\text { Di } \\
\text { (RX5DAY) }\end{array}$ & $\begin{array}{c}\text { Critical } \\
\text { Value of } \\
\text { Di }\end{array}$ & $\begin{array}{c}\text { H1 } \\
\text { (RX5DAY) }\end{array}$ \\
\hline region1 & 2 & $\begin{array}{c}\text { Songpa } \\
(1.00) \text { Heishui } \\
(1.00)\end{array}$ & 1.333 & -0.6 & 2 & $\begin{array}{l}\text { Songpan } \\
(1.00) \\
\text { Heishui } \\
(1.00)\end{array}$ & 1.33 & 0.8 \\
\hline region2 & 3 & $\begin{array}{c}\text { Maoxian (1.00) } \\
\text { Wenchuan (1.00) } \\
\text { Lixian } \\
(1.00)\end{array}$ & 1.333 & -0.29 & 3 & $\begin{array}{c}\text { Maoxian (1.00) } \\
\text { Wenchuan (1.00) } \\
\text { Lixian } \\
(1.00)\end{array}$ & 1.33 & 0.30 \\
\hline region3 & 15 & \begin{tabular}{|c|} 
Shuangliu (0.58) \\
Xinjin \\
$(0.12)$ \\
Dujiangyan \\
(2.14) Pengzhou \\
$(0.95)$ \\
Wenjiang (0.99) \\
Chongzhou \\
(0.22) \\
Dayi \\
$(0.51)$ Qionglai \\
(0.97) Pujiang \\
$(1.78)$ Minshan \\
$(1.53)$ Meishan \\
$(0.14)$ Pengshan \\
$(1.60)$ Dangling \\
(1.54) Qingshen \\
(0.72) \\
Leshan \\
(1.22)
\end{tabular} & 3 & -0.09 & 13 & \begin{tabular}{|c|} 
Shuangliu (0.52) \\
Xinjin \\
$(0.06)$ \\
Dujiangyan \\
$(1.83)$ Pengzhou \\
$(0.89)$ \\
Wenjiang $(0.86)$ \\
Chongzhou \\
$(0.15)$ \\
Dayi \\
$(0.62)$ \\
Qionglai \\
$(0.97)$ \\
Pujiang \\
$(1.20)$ \\
Minshan \\
$(1.87)$ \\
Meishan \\
$(1.41)$ \\
Dangling (2.01) \\
Leshan \\
$(1.07)$
\end{tabular} & 3 & -0.03 \\
\hline region4 & 5 & \begin{tabular}{|c|} 
Jingyan \\
(0.99) Qianwei \\
(1.28) Mabian \\
(1.31) Muchuan \\
(1.08) \\
Yibin \\
$(0.33)$
\end{tabular} & 1.333 & -0.13 & 7 & \begin{tabular}{|c|} 
Pengshan (1.31) \\
Qingshen (0.35) \\
Jingyan \\
$(1.16)$ \\
Qianwei \\
$(1.62)$ \\
Mabian \\
$(0.94)$ \\
Muchuan (1.15) \\
Yibin \\
$(0.46)$
\end{tabular} & 1.333 & 0.82 \\
\hline
\end{tabular}


Table 5. Monte Carlo simulation results of distribution lines in four hydrometeorological consistent regions of the MRB

\begin{tabular}{|c|c|c|c|c|c|c|c|c|c|}
\hline \multirow{2}{*}{ index } & \multirow{2}{*}{ linearity } & \multicolumn{2}{|c|}{ Region1 } & \multicolumn{2}{|c|}{ Region2 } & \multicolumn{2}{|c|}{ Region3 } & \multicolumn{2}{|c|}{ Region4 } \\
\hline & & RX1DAY & RX5DAY & RX1DAY & RX5DAI & RX1DA & RX5DAI & RX1DAY & RX5DAY \\
\hline \multirow{5}{*}{7} & GLO & -0.81 & 0.34 & -0.02 & 0.02 & 1.30 & 1.76 & .20 & 1.38 \\
\hline & GEV & -1.86 & -1.43 & -0.82 & -0.82 & -1.62 & -0.96 & -1.19 & -1.25 \\
\hline & GNO & -1.88 & -0.99 & -0.98 & -0.98 & -1.80 & -1.25 & -1.48 & -1.03 \\
\hline & PE3 & -2.10 & -1.00 & -1.35 & -1.88 & -1.35 & -2.11 & -2.10 & -1.31 \\
\hline & GPD & -4.08 & -4.64 & -2.70 & -5.45 & -7.87 & -6.78 & -4.34 & -6.52 \\
\hline \multicolumn{2}{|c|}{ oution Linearity } & GLO & GLO & GLO & GLO & GLO & GEV & GLO & GNO \\
\hline
\end{tabular}

The traditional at-site hydrological frequency analysis (a2-d2 in Figure 5) refers to the calculation of all stations using the same frequency function instead of zoning the stations. It can be seen that the 20-year and 100-year maximum distribution of RX1DAY and RX5DAY was mainly distributed in the middle of the Min River, followed by the lower reaches of the basin, and the upper reaches of the basin were relatively small. The spatial distribution was consistent with the results of regional frequency analysis.
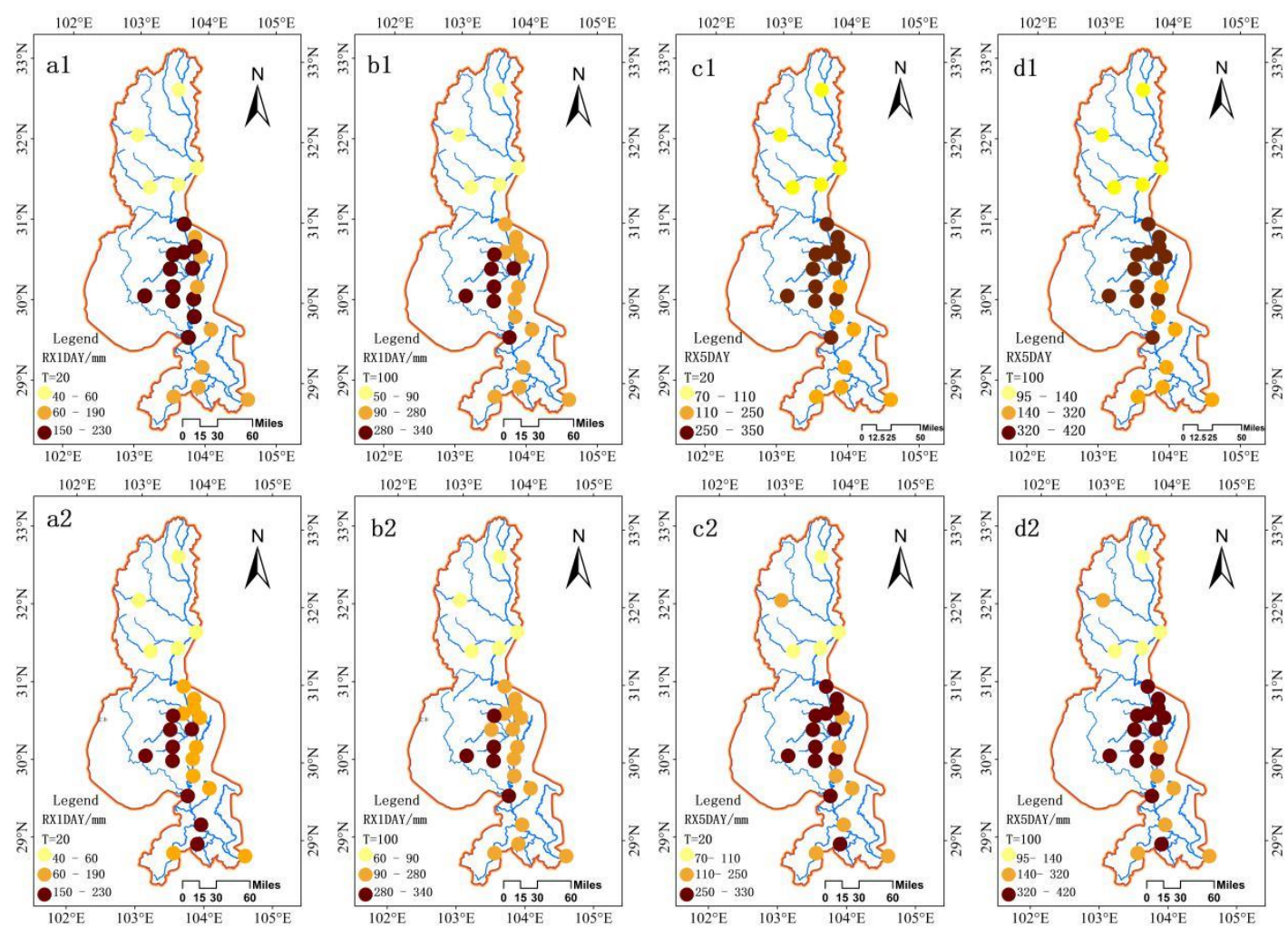

Figure 5. Spatial distribution of estimated precipitation with RXIDAY and RX5DAY recurrence periods of 20 and 100 years 
By comparing the estimated precipitation calculated by the two methods, the extreme precipitation in the middle reaches of the basin by traditional at-site hydrological frequency analysis was lower than that by regional frequency analysis, and slightly higher than that by regional frequency analysis in the lower reaches of the basin. To a certain extent, the difference between the upper, middle, and lower reaches of the basin was reduced, the spatial difference was averaged, and the extreme precipitation in the middle reaches of the basin was underestimated. It is unsafe to estimate the estimated precipitation based on the spatial distribution of extreme precipitation. The regional frequency analysis can effectively avoid the problem that the estimated precipitation estimated by the overall data neglects the spatial distribution of the overall internal changes in the context of climate change.

\section{Discussion}

The MRB is located in the transition zone between the Qinghai-Tibet Plateau terrain and the eastern plain of China. The upper reaches of the basin are characterized by low humidity and less external water vapor transport. The middle and lower reaches of the basin are affected by tropical monsoon, subtropical monsoon, and plateau monsoon. The complex climate and special geographical location provide conditions for the uneven spatial distribution of extreme precipitation events. The frequency of extreme precipitation events in the lower and middle reaches of the MRB is significantly higher than that in the upper reaches. This may be related to the fact that the upper reaches of the MRB have low humidity and low water vapor transport due to the high altitude. Meanwhile, the intensity of extreme precipitation events in the MRB is the largest in the middle reaches, especially in the continuous extreme precipitation. The intensity of extreme precipitation events in the lower reaches is larger than that in the upper reaches. This is mainly because the middle reaches of the MRB is located in the rainstorm area in the northwest of the basin, which is affected by the eastern side of the Qinghai-Tibet Plateau and is a rainstorm area far from the ocean in China, resulting in the intensity of extreme precipitation events in the middle reaches of the MRB (Peng et al., 1985; Li et al., 2011).

The spatial distribution of extreme precipitation index in the MRB is quite different. The spatial variation trend of extreme precipitation in the MRB was that the spatial difference of RX5DAY increases, while the spatial difference of RX1DAY decreases. The main factors affecting the spatial variation of extreme precipitation were the spatial variation of $\mathrm{R} 10 \mathrm{~mm}$ and WD.

According to the trend analysis, the average characteristics of extreme precipitation in the MRB have changed from short-term extreme precipitation to persistent extreme precipitation. The main reasons for this change are the increase of the WD, the CWD and the R10mm, especially the increase of the R10mm. 
At the same time, with the development of urbanization, Dujiangyan, Meishan and Leshan in the middle reaches of the MRB and Yibin Station in the lower reaches of the MRB are affected by the urban heat island effect, which further makes the distribution of precipitation uneven, thus affecting the distribution of extreme precipitation (Shou et al., 2012; Zhao et al., 2019).

In addition, the analysis methods used in this paper are uncertain, and it is necessary to further study the characteristics of extreme precipitation from different perspectives by various methods. Based on the results of this study, the relationship between extreme precipitation and atmospheric circulation needs to be further verified. At the same time, correlation analysis can be used to find out which factors are related to extreme precipitation.

Acknowledgements. This research was financially supported by National Natural Science Foundation of China (No. 50979062); Sichuan Key Laboratory of Rainstorm, Drought and Flood Disasters in Plateau and Basin (No. Provincial Heavy Laboratory 2018-Youth-09); Sichuan Science and Technology Department's Key Research and Development Project (No. 2018SZ0343); Sichuan Meteorological Service Center Project (No. SCQF2019007).

\section{REFERENCES}

[1] Croitoru, A-E., Chiotoroiu, B-C., Todorova, V. I., Torica, V. (2013): Changes in precipitation extremes on the Black Sea Western Coast. - Global and Planetary Change 10-19.

[2] Alexander, L. V., Zhang, X., Peterson, T. C., Gleason, B., Klein Tank, A. M. G., Haylock, M., Collins, D., Trewin, B., Rahimzadeh, F., Tagipour, A., Kumar, K. R., Revadekar, J. (2006): Global observed changes in daily climate extremes of temperature and precipitation. - Journal of Geophysical Research 111(D5): D05109.

[3] Bai, L. Y., Rong, Y. S. (2015): Reanalysis of the characteristics of extreme rainfall in the Yangtze River basin during recent 50 years. - Journal of Water Resources Research 4(1): 88-100.

[4] Bonsal, B. R., Zhang, X. B., Vincent, L. A., Hogg, W. D. (2001): Characteristic of daily and exreme temperature over Canada. - Climate 4(9): 1959-1976.

[5] Burn, D. H. (2008): Climatic influences on stream flow timing in the headwaters of the Mackenzie River Basin. - J. Hydrol. 352: 225-238.

[6] Changnon, S. A., Pielk, R. A., Changnon, D., Sylves, L. T., Pulwarty, R. (2000): Human factors explain the increased losses from weather and climate extremes. - Bulletin of the American Meteorological Society 81(3): 437-442.

[7] Chen, Y., Xu, C., Hao, X., Li, W., Chen, Y., Zhu, C., Ye, Z. (2009): Fifty-year climate change and its effect on annual runoff in the Tarim River Basin, China. - Quaternary International 208(1-2): 53-61. 
[8] Chen, H., Sun, J., Chen, X., Zhou, W. (2012): CGCM projections of heavy rainfall events in China. - International Journal of Climatology 32(3): 441-450.

[9] Chen, X. (2014): Study on high-risk regionalization of heavy rainfall based on regional linear moment method and its application in Guangxi. - Nanjing University of Information Science and Technology, Nanjing.

[10] Chu, H. J., Pan, T. Y., Liu, J. J. (2012): Change-point detection of long-duration extreme precipitation and the effect on hydrologic design: a case study of south Taiwan. Stochastic Environmental Research and Risk Assessment 2626(8): 1123-1130.

[11] Cunnane, C. (1989): Statistical distributions for flood frequency analysis. - Operational Hydrology Report 44(11): 369-369.

[12] Fu, G., Yu, J., Yu, X., Ouyang, R., Zhang, Y., Wang, P., Liu, W., Min, L. (2013): Temporal variation of extreme rainfall events in China, 1961-2009. - Journal of Hydrology 487: 48-59.

[13] He, Z., He, J. (2014): Temporal and spatial variation of extreme precipitation in the Yellow River basin from 1960 to 2012. - Resources Science 3: 490-501.

[14] Huang, Q., Chen, Z. (2014): Regional study on the trends of extreme temperature and precipitation events in the Pearl River basin. - Advances in Earth Science 8: 956-967.

[15] IPCC. (2013): Climate Change 2013: The Physical Science Basis. - In: Stocker, T. F., Qin, D., Plattner, G. K., Tignor, M., Allen, S. K., Boschung, J., Nauels, A., Xia, Y., Bex, V., Midgley, P. M. (eds.) Contribution of Working Group I to the Fifth Assessment Report of the Intergovernmental Panel on Climate Change. Cambridge University Press, Cambridge, United Kingdom and New York.

[16] Kampata, J. M., Parida, B. P., Moalafhi, D. B. (2008): Trend analysis of rainfall in the head streams of the Zambezi River Basin in Zambia. - Phys. Chem. Earth 33: 621-625.

[17] Karl, T. R., Knight, R. W. (1998): Secular trends of precipitation amount, frequency, and intensity in the USA. - Bull Am Met Soc 79: 231-241.

[18] Kendall, M. G. (1970): Rank Correlation Methods. - Griffin, London.

[19] Li, Y. Q., Zhang, X. C. (2011): Main Advances in the Research of "Yaan Sky Leakage". - Torrential Rain and Disasters 30(4): 289-295.

[20] Li, X. Z., Liu, X. D. (2012): Numerical simulations of extreme precipitation in eastern China under A1B scenario. - Journal of Tropical Meteorology 28(3): 379-391.

[21] Li, Z., Zheng, F. L., Liu, W. Z., Jiang, D. (2012): Spatially downscaling GCMs outputs to project changes in extreme precipitation and temperature events on the Loess Plateau of China during the 21st Century. - Global and Planetary Change 82-83: 65-73.

[22] Li, M., Lin, B. Z., Shao, Y. H. (2015): Study on Spatial Continuity of Precipitation Quantile Estimates Based on Regional L-moments Analysis. - Journal of China Hydrology 35(4): 14-19.

[23] Li, S., Yang, S., Liu, X. (2015): Spatiotemporal variability of extreme precipitation in north and South of the Qinling-Huaihe region and influencing factors during 1960-2013. - Progress in Geography 3: 354-363. 
[24] Lin, B., Bonnin, G. M., Martin, D. L. (2006): Regional Frequency Studies of Annual Extreme Precipitation in the United States Based on Regional L-Moments Analysis. ASCE Proceedings, Omaha, NE, USA.

[25] Luyao, B., Yanshu, R. (2015): Reanalysis of the Characteristics of Extreme Rainfall in the Yangtze River Basin during Recent 50 Years. - Journal of Water Resources Research 2015(4): 88-100.

[26] Mann, H. B. (1945): Non-parametric tests against trend. - Econometrica 13: 245-259.

[27] Millett, B., Johnson, W. C., Guntenspergen, G. W. (2009): Climate trends of the North American prairie pothole region 1906-2000. - Climatic Change 93: 243-267.

[28] Pal, I., Al-Tabbaa, A. (2011): Monsoon rainfall extreme indices and tendencies from 1954-2003 in Kerala, India. - Climatic Change 106(3): 407-419.

[29] Pan, X., Yin, Y. X., Wang, X. J. (2017): Spatio-temporal characteristics and future trend of extreme precipitation in the Yangtze river basin during 1960 to 2010. - Resources and Environment in the Yangtze Basin 26(3): 436-444.

[30] Peng, G. K., Li, Z. Y., Chai, F. X. (1985): The relationship between topography and precipitation in ya'an district. - Plateau Meteorology 4(3): 230-240.

[31] Qian, W., Lin, X. (2005): Regional trends in recent precipitation indices in China. Meteorology and Atmospheric Physics 90(30): 193-207.

[32] Qing, T. (2016): Precipitation and temperature changes in the major Chinese river basins during 1957-2013 and links to sea surface temperature. - Journal of Hydrology 536: 208-221.

[33] Shao, Y. H., Wu, J. M., Li, M. (2016): Frequency Analysis of Extreme Precipitation in Huaihe River Basin Based on Hydrometeorological Regional L-moments Method. Journal of China Hydrology 36(6): 16-23.

[34] Shou, Y. X., Zhang, D. (2012): Recent advances in understanding urban heat island effects with some future prospects. - Acta Meteorologica Sinica 70(3): 338-353.

[35] Su, B. D., Jiang, T. G. Y., Chen, Z. H. (2006): Observed trends of precipitation extremes in the Yangtze River basin during 1960 to 2004. - Advances in Climate Change Research 2(1): 9-14.

[36] Tian, Q., Prange, M., Merkel, U. (2016): Precipitation and temperature changes in the major Chinese river basins during 1957-2013 and links to sea surface temperature. Journal of Hydrology 536: 208-221.

[37] Tramblay, Y., Badi, W., Driouech, F., Adlouni, S. E., Neppel, L., Servat, E. (2012): Climate change impacts on extreme precipitation in morocco. - Global and Planetary Change 82-83: 1-114.

[38] Vijay, K., Sharad, K. J. (2010): Trends in seasonal and annual rainfall and rainy days in Kashmir Valley in the last century. - Quat. Int. 212: 64-69.

[39] Wang, Z., Ding, Y., He, J. (2004): An updating analysis of the climate change in China in recent 50 years. - Acta Meteorological Sinica 62(2): 228-236.

[40] Wang, S. J. (2009): Changing pattern of the temperature, precipitation and runoff in Chuanjiang Section of the Yangtze River. - Resour. Sci. 31: 1142-1149. 
[41] Wu, H., Soh, L. K., Samal, A., Chen, X. H. (2008): Trend analysis of streamflow drought events in Nebraska. - Water Resour. Manage. 22: 145-164.

[42] Wu, X., Wang, Z., Zhou, X., Lai, C., Lin, W., Chen, X. (2016): Observed changes in precipitation extremes across 11 basins in China during 1961-2013. - Int. J. Climatol 36: 2866-2885.

[43] Xiong, L. H., Guo, S. L., Wang, C. J. (2004): Advance in regional flood frequency analysis from abroad. - Advances in Water Science 2: 2.

[44] Xu, Z. X., Li, J. Y., Liu, C. M. (2007): Long-term trend analysis for major climate variables in the Yellow River basin. - Hydrol. Processes 21: 1935-1948.

[45] Xu, Z., Liu, Z., Fu, G., Chen, Y. (2010): Trends of major hydroclimatic variables in the tarim river basin during the past 50 years. - Journal of Arid Environments 74(2): 1-267.

[46] Yang, T., Chen, X., Yang, H. W., Xie, H. W. (2009): Regional flood frequency analysis in Pearl River Delta region based on L-moments approach. - Journal of Hohai University (Natural Sciences) 37(6): 615-619.

[47] Yang, T., Hao, X., Shao, Q., Xu, C., Zhao, C., Chen, X., Wang, W. (2012): Multi-model ensemble projections in temperature and precipitation extremes of the Tibetan Plateau in the 21st century. - Global and Planetary Change 80-81: 1-13.

[48] Yu, R. C. (2004): Tropospheric cooling and summer monsoon weakening trend over East Asia. - Geophysical Research Letters 31(22): L22212.

[49] Zengxin, Z. (2011): Evaluating the non-stationary relationship between precipitation and stream flow in nine major basins of China during the past 50 years. - Journal of Hydrology 409: 81-93.

[50] Zhai, P. M., Ren, F. M., Zhang, Q. (1999): Detection of trends in China's precipitation extremes. - Acta Meteorologica Sinica 52(2): 208-216.

[51] Zhai, P., Zhang, X., Wan, H., Pan, X. (2005): Trends in total precipitation and frequency of daily precipitation extremes over china. - Journal of Climate 18(7): 1096-1108.

[52] Zhang, Y., Xu, Y., Dong, W. (2006): A future climate scenario of regional changes in extreme climate events over China using the PRECIS climate model. - Geophysical Research Letters 33(24): L24702.

[53] Zhang, Y., Du, X. R. (2008): Analysis of temperature and precipitation change over last 50 years in Leshan City. - Plateau Mt. Meteor. Res. 28(3): 68-71.

[54] Zhang, M., Wei, X., Sun, P., Liu, S. (2012): The effect of forest harvesting and climatic variability on runoff in a large watershed: the case study in the upper Minjiang river of Yangtze river basin. - Journal of Hydrology (Amsterdam): 464-465.

[55] Zhao, C. P., Zhou, J. H., Li, Z. (2019) Influence of Urbanization on the Change of Rainstorm in Taiyuan. - Journal of Arid Meteorology 37(1): 109-118. 